\title{
Correction to: Experimental study of bitumen emulsion- cement mortars: mechanical behaviour and relation to mixtures
}

\author{
Chiara Mignini • Fabrizio Cardone $[$ - Andrea Graziani $\mathbb{B}$
}

Published online: 27 March 2019

(C) RILEM 2019

Correction to: Materials and Structures (2018) 51:149 https://doi.org/10.1617/s11527-018-1276-y

The article Experimental study of bitumen emulsioncement mortars: mechanical behaviour and relation to mixtures, written by Chiara Mignini, Fabrizio Cardone, Andrea Graziani, was originally published online without Open Access. After publication in volume 51, article ID 149 RILEM decided to grant the author to opt for open choice and to make the article an open-access publication. Therefore, the copyright of the article has been changed to (C) The Author(s) 2018 and the article is forthwith distributed under the terms of the Creative Commons Attribution 4.0 International License (http://creativecommons.org/licenses/by/4.0/), which permits use, duplication, adaptation, distribution and reproduction in any medium or format, as long as you give appropriate credit to the original author(s) and the source, provide a link to the Creative Commons license, and indicate if changes were made.

Publisher's Note Springer Nature remains neutral with regard to jurisdictional claims in published maps and institutional affiliations.
The original article can be found online at https://doi.org/10.1617/s11527-018-1276-y.

C. Mignini · F. Cardone · A. Graziani $(\bowtie)$

Dipartimento di Ingegneria Civile Edile e Architettura Via

Brecce Bianche, Università Politecnica delle Marche,

60131 Ancona, Italy

e-mail: a.graziani@univpm.it 